\title{
Eficiência de Utilização da Energia Metabolizável para Ganho de Peso e Exigências de Energia Metabolizável e Nutrientes Digestíveis Totais de Bovinos $F_{1}$ Simental $x$ Nelore ${ }^{1}$
}

\section{Marcelo de Andrade Ferreira², Sebastião de Campos Valadares Filho ${ }^{3}$, José Fernando Coelho da Silva ${ }^{3}$, Rilene Ferreira Diniz Valadares ${ }^{4}$, Mário Fonseca Paulino ${ }^{3}$, Paulo Roberto Cecon ${ }^{5}$, Elaine Barboza Muniz ${ }^{6}$}

RESUMO - O objetivo deste trabalho foi estimar a eficiência de utilização da energia metabolizável (EM), para ganho de peso, e as exigências de energia metabolizável e nutrientes digestíveis totais de bovinos $\mathrm{F}_{1}$ Simental x Nelore, não-castrados, alimentados com rações contendo diferentes níveis de concentrado. Foram utilizados 29 animais com, em média, idade de 17 meses e peso vivo inicial de $354 \mathrm{~kg}$. Cinco animais foram abatidos ao início do experimento, como referência, e o restante foi alimentado à vontade e distribuído nos tratamentos, de forma inteiramente casualizada, de acordo com o nível de concentrado na ração: 25; 37,5; 50; 62,5; e 75\%. Os animais foram abatidos quando atingiram o peso de $500 \mathrm{~kg}$. As concentrações de energia líquida das rações foram calculadas e as eficiências de utilização da energia metabolizável para ganho de peso foram estimadas, por análise de regressão, entre as energias líquidas para ganho, em relação à energia metabolizável (EM) das rações. As exigências de EM para ganho de um quilograma de peso de corpo vazio aumentaram, à medida que se elevou o peso corporal dos animais e diminuíram, para mesmo peso vivo, à medida que se elevaram os níveis de concentrado nas rações. Estimaram-se as eficiências de utilização da energia metabolizável para ganho de peso em: 0,27; 0,26;0,36; 0,39; e 0,42. O nível de concentrado melhorou a eficiência de utilização da EM para ganho de peso.

Palavras-chave: bovinos mestiços, eficiência, energia metabolizável, nível de concentrado, rações

\section{Efficiency of Metabolizable Energy Utilization for Weight Gain and Requirements of Metabolizable Energy and Total Digestible Nutrients in $F_{1}$ Simental $x$ Nellore Bulls}

\begin{abstract}
The objective of this work was to estimate the efficiency of metabolizable energy utilization (ME) for weight gain, and the requirements of metabolizable energy and total digestible nutrients in $\mathrm{F}_{1}$ Simental x Nellore bulls fed diets containing different concentrate levels. Twenty-nine animals averaging 17 of age and initial live weight of $354 \mathrm{~kg}$ were used. Five animals were slaughtered in the beginning of the experiment, as a reference, and the remainders were full fed and allotted to a completely randomized design, according to the dietary concentrate level: $25,37.5,50,62.5$, and $75 \%$. Animals were slaughtered when they reached $500 \mathrm{~kg}$. The dietary net energy concentrations were calculated, and the utilization efficiencies of the metabolizable energy for weight gain were estimated by regression analysis, among the net energies for gain, on the dietary metabolizable energy (ME). The ME requirements for 1 kilogram of empty body weight gain increased as the animal body weights raised, and decreased for the same live weight as the dietary concentrate levels increased. The efficiencies of metabolizable energy utilization estimated for weight gain were: .27, .26, .36, .39, and .42. The concentrate level improved the efficiency of ME utilization for weight gain.
\end{abstract}

Key Words: crossbred bulls, efficiency, metabolizable energy, level of concentrate, diets

\section{Introdução}

A energia metabolizável(EM) foi definida como a energia bruta dos alimentos, menos a energia perdida nas fezes, a energia urinária e a perda de energia pelos gases (NRC, 1981), ou seja, estimativa da energia disponível para o animal (NRC, 1996). A energia líquida (EL) do alimento seria a fração da energia metabolizável utilizada pelo animal, para mantença e produção, após as perdas do incremento calórico (NRC, 1981).

As exigências energéticas dos animais são as mais difíceis de serem determinadas, pois a eficiência de utilização da energia para os vários processos fisiológicos - mantença, crescimento, engorda e lactação - é variável, além do fato de haver muitas outras interferências, como o clima, os exercícios do animal e a concentração de energia metabolizável do

\footnotetext{
${ }^{1}$ Parte da Tese apresentada pelo primeiro autor à UFV para obtenção do título "Doctor Scientiae".

${ }^{2}$ Professor da UFRPE.

${ }^{3}$ Professor do Departamento de Zootecnia da UFV.

${ }^{4}$ Professor do Departamento de Medicina Veterinária da UFV.

${ }^{5}$ Professor do Departamento de Informática da UFV.

${ }^{6}$ Bolsista de Aperfeiçoamento.
} 
alimento (COELHO DA SILVA e LEÃO, 1979).

Em 1963, Lofgreen e Garret introduziram o sistema de energia líquida para crescimento e engorda de gado de corte (LOFGREEN e GARRET, 1968). O sistema separa os requerimentos de energia para mantença e ganho de peso. A soma das necessidades de mantença e ganho representam as exigências de energia líquida dos animais. Conhecendo-se as exigências líquidas e levando-se em consideração os fatores de eficiência de utilização da energia do alimento para mantença e ganho, obtêm-se as exigências dietéticas.

A exigência energética de mantença pode ser definida como a quantidade de energia do alimento que não resultará em ganho, nem em perda de energia corporal (NRC, 1984). De acordo com LOFGREEN e GARRET (1968), os requerimentos de mantença eqüivaleriam à produção de calor do animal em jejum. Em animais alimentados, a produção de calor é derivada do metabolismo basal, incremento calórico e calor produzido pelas atividades do animal. Não havendo consumo de alimentos, o incremento calórico é igual a zero e os componentes da produção de calor são o metabolismo basal e o calor produzido pelas atividades voluntárias do animal, que são consideradas iguais aos requerimentos de energia líquida para mantença.

Os requerimentos de energia líquida para mantença, para o gado de corte, têm sido estimados como $77 \mathrm{kcal}$ por unidade de tamanho metabólico (GARRET, 1980; NRC, 1984), apesar destas exigências variarem com o sexo, a raça, a idade, a composição corporal e o nível nutricional do animal (SOLIS et al., 1988).

Para o AFRC (1993), os requerimentos de mantença envolveria o metabolismo do jejum e as atividades voluntárias, sendo influenciados pelo peso vivo, com acréscimo de $15 \%$ para o macho nãocastrado. O NRC (1996) também acrescentou 15\% para machos não-castrados.

As exigências de energia líquida para taxa de ganho de peso diferem, para animais de mesmo peso vivo, em virtude das diferenças na composição do ganho de peso (GARRET et al., 1959), que é influenciada por vários fatores, principalmente pela raça, pelo sexo, pelo estado fisiológico e pela dieta (ROBELIN e GEAY, 1983).

Dessa forma, as diferenças na composição do ganho de peso são responsáveis pela maior exigência de energia em animais em estádio mais avançado de maturidade fisiológica, pelas maiores exigências de animais precoces, em relação aos tardios a mesmo peso vivo, e pela maior exigência das fêmeas em relação aos machos inteiros (LANA, 1991).

A eficiência de utilização da energia metabolizável da ração não está muito bem estabelecida para ruminantes. O NRC (1984) mostrou valores de eficiência de utilização da energia metabolizável para mantença, variando de 57,6 a 68,6\%, e, para ganho, de 29 a $47,3 \%$, para rações com o teor de EM, variando de 2,0 a 3,2 Mcal/kg de matéria seca.

GARRET (1980) relatou que resultados experimentais mostraram que a eficiência de utilização da EM na síntese de proteína variou entre 10 e $40 \%$, enquanto, para síntese de gordura, esta variação estava entre 60 e $80 \%$.

Segundo RATTRAY e JOYCE (1976), os ganhos de peso associados com altas deposições de gordura foram mais eficientes, energeticamente, mas menos eficientes em relação à conversão de alimentos, em peso vivo, quando comparados a ganhos com pequena deposição de gordura. Isto ocorre porque os tecidos adiposos, onde ocorre grande parte do aumento de peso vivo, contêm teores mais elevados de matéria seca (LANA, 1991) que os músculos (80 vs $30 \%$, aproximadamente).

A eficiência de utilização da energia metabolizável deve ser considerada para se determinarem as exigências dietéticas. Analisando-se os trabalhos publicados em condições brasileiras por BOIN (1995) e FONTES (1995), observou-se que, apesar de já terem sido publicados vários dados sobre exigências nutricionais de bovinos no Brasil, existe carência de fatores para conversão das exigências líquidas em dietéticas.

Assim, o objetivo deste trabalho foi determinar a eficiência de utilização da energia metabolizável para ganho de peso e as exigências de energia metabolizável e de nutrientes digestíveis totais para bovinos $F_{1}$ Simental x Nelore, não-castrados, alimentados com rações contendo diferentes níveis de concentrado.

\section{Material e Métodos}

O local do experimento, as rações utilizadas, a proporção de ingredientes nas mesmas, o manejo dos animais, as características dos animais utilizados, o consumo de nutrientes, os procedimentos de abate e as coletas de amostra de tecido animal e vegetal, as análises químicas, o delineamento experimental e as análises estatísticas foram descritos por FERREIRA et al. (1999a,b).

As concentrações de energia líquida das rações foram calculadas de acordo com HARRIS (1970).

Para determinação da energia líquida de mantença, 
foi utilizado o valor de $77 \mathrm{kcal} / \mathrm{kg}^{0,75}$, adotado pelo NRC (1984), determinado por LOFGREEN e GARRET (1968).

$\mathrm{O}$ teor de EM das rações foi obtido segundo SNIFFEN et al.(1992), considerando-se 1 quilograma de NDT igual a 4,409 Mcal de energia digestível (ED) e 1 Mcal de ED igual a 0,82 Mcal de EM. Para o cálculo do consumo de NDT (cNDT), empregou-se a seguinte fórmula:

$\mathrm{cNDT}=(\mathrm{cPB}-\mathrm{PBf})+2,25(\mathrm{cEE}-\mathrm{EEf})+(\mathrm{cCHO}-\mathrm{CHOf})$,

em que

$\mathrm{cPB}, \mathrm{cEE}$, e $\mathrm{cCHO}=$ consumos de proteína bruta, extrato etéreo e carboidratos totais, respectivamente; e

PBf, EEf e CHOf = excreções fecais de proteína bruta, extrato etéreo e carboidratos totais, respectivamente; sendo a concentração de NDT, nas rações, determinada pela relação entre o consumo de NDT e o consumo de matéria seca.

A determinação dos teores de $\mathrm{PB}, \mathrm{EE}$ e $\mathrm{CHO}$ nas fezes foi feita em um ensaio de digestibilidade por TIBO, em 1997 (dados ainda não publicados), no qual se utilizaram cinco animais de mesma constituição genética dos utilizados no ensaio de determinação das exigências de energia líquida, alimentados com as mesmas rações. Os animais foram distribuídos em quadrado latino ( 5 X 5), com cinco níveis de concentrado $(25 ; 37,5 ; 50 ; 62,5$; e $75 \%)$ e cinco períodos. Cada período experimental teve duração de 14 dias, sendo 10 de adaptação e quatro para coleta de fezes. Como indicador, foram utilizados $20 \mathrm{~g} \mathrm{de}_{2} \mathrm{O}_{3}$, colocados diariamente no rúmen de cada animal, em duas doses de $10 \mathrm{~g}$ cada, fornecidas durante os últimos sete dias de adaptação e os quatro de colheita.

A ingestão de matéria seca suficiente para manter o equilíbrio de energia foi calculada dividindo-se o consumo de EM, suficiente para mantença $\left(131 \mathrm{kcal} / \mathrm{kg}^{0,75}\right)$, pela concentração de EM(kcal/gMS) da ração usada em cada tratamento. Posteriormente, calculou-se o teor de energia líquida de mantença (Elm), dividindo-se a produção de calor do jejum $\left(77 \mathrm{kcal} / \mathrm{kg}^{0,75}\right)$ pelo consumo de matéria para manter o equilíbrio de energia expresso em $\mathrm{g} \mathrm{MS} / \mathrm{kg}^{0,75}$.

O cálculo da energia líquida de ganho, para cada tratamento, foi efetuado subtraindo-se o consumo voluntário de matéria seca $\left(\mathrm{g} \mathrm{MS} / \mathrm{kg}^{0,75}\right)$ do consumo de matéria seca suficiente para manter o equilíbrio de energia ( $\left.\mathrm{g} \mathrm{MS} / \mathrm{kg}^{0,75}\right)$. O teor de energia líquida para ganho de peso foi calculado dividindo-se o balanço energético diário (energia retida por dia) em $\mathrm{kcal} / \mathrm{kg}^{0,75}$ pelo consumo de matéria seca, além das necessidades de mantença, expresso em $\mathrm{g} \mathrm{MS} / \mathrm{kg}^{0,75}$.
A eficiência de utilização da EM, para ganho de peso $\left(\mathrm{K}_{\mathrm{f}}\right)$, foi estimada por regressão do teor de energia líquida, em função do teor de energia metabolizável das rações, segundo GARRET (1980).

As exigências de EM foram obtidas dividindose as exigências de energia líquida para ganho de peso pelas eficiências de utilização da EM para ganho $\left(K_{f}\right)$. As exigências de NDT foram calculadas dividindo-se as exigências de energia metabolizável por 0,82 e, posteriormente, dividindo-se as exigências de energia digestível por 4,409.

\section{Resultados e Discussão}

Na Tabela 1 são apresentados os teores de NDT, as concentrações de energia metabolizável (EM) e os valores calculados para energia líquida de mantença (Elm), a energia líquida de ganho (Elg) e as eficiências de utilização da energia para ganho de peso $\left(\mathrm{K}_{\mathrm{f}}\right)$.

Nas tabelas do NRC (1984) são encontrados os valores de Elm e Elg de uma ração com teor de EM de 2,60 Mcal/kg MS, em 1,69 e 1,08 Mcal/kg MS, respectivamente. Os valores encontrados no presente traba1ho, para ração com teor de EM de 2,58 Mcal $/ \mathrm{kg} \mathrm{MS}$, que foram de 1,52 e 0,99 Mcal/kg MS para Elm e Elg, respectivamente, encontram-se muito próximos daqueles constantes das tabelas do NRC (1984).

Verificou-se que as eficiências até o nível de 50\% de concentrado aumentaram de forma mais pronunciada em relação ao nível de 75\%. Segundo RATTRAY e JOYCE (1976), os ganhos de peso em que ocorreram altas deposições de gordura foram mais eficientes energeticamente. Como foi verificado por FERREIRA et al. (1998b), a partir do nível de $50 \%$ de concentrado, ocorreu deposição de gordura relativamente constante, observando-se pequeno aumento na deposição de proteína, o que pode explicar a pequena variação observada nos valores de eficiência de utilização da energia metabolizável, a partir do nível de $50 \%$ de concentrado.

A equação e o gráfico resultantes da regressão da energia líquida de ganho (Elg) em função da energia metabolizável da ração são apresentados na Figura 1. Utilizando-se os valores de EM das rações, na equação da Figura 1, foram estimados os respectivos valores de eficiência de utilização da EM para ganho $(\mathrm{kg})$ de 0,$27 ; 0,26 ; 0,36 ; 0,39$; e 0,42 .

Baseando-se no valor de $0,077 \mathrm{Mcal} / \mathrm{kg}^{0,75}$, como energia líquida de mantença, na eficiência de utilização da energia metabolizável para mantença de 0,59, e acrescentando $15 \%$, como preconizado pelo AFRC 
Tabela 1 - Teor de NDT e concentração de energia metabolizável (EM), obtidas para os níveis de concentrado das rações (NC), concentração de energia líquida para mantença (Elm) e ganho (Elg), calculada para cada nível de concentrado nas rações, e valores das eficiências de utilização da EM para ganho $\left(\mathrm{K}_{\mathrm{f}}\right)$, observados para cada nível de concentrado nas rações (NC)

Table 1 - Content of TDN and metabolizable energy (ME) concentration, obtained for the dietary levels of concentrate, net energy concentration for maintenance and gain, calculated for each dietary level of concentrate, and values of efficiency of EM utilization for gain, observed for each level of concentrate in the diet

\begin{tabular}{|c|c|c|c|c|c|}
\hline \multirow{3}{*}{$\begin{array}{l}\mathrm{NC}(\%) \\
C L\end{array}$} & \multirow{3}{*}{$\begin{array}{c}\text { NDT(\%) } \\
T D N\end{array}$} & \multirow{2}{*}{\multicolumn{3}{|c|}{$\begin{array}{c}\mathrm{Mcal} / \mathrm{kg} \text { MS } \\
\text { Mcal/kg DM }\end{array}$}} & \multirow{3}{*}{$\begin{array}{c}\text { Eficiência (\%) } \\
\text { Efficiency } \\
\mathrm{K}_{\mathrm{f}}\end{array}$} \\
\hline & & & & & \\
\hline & & EM & Elm & ELg & \\
\hline 25 & 63,08 & 2,28 & 1,34 & 0,53 & 0,23 \\
\hline 37,5 & 62,51 & 2,26 & 1,33 & 0,66 & 0,29 \\
\hline 50 & 67,31 & 2,43 & 1,43 & 0,90 & 0,37 \\
\hline 62,5 & 71,33 & 2,58 & 1,52 & 0,99 & 0,38 \\
\hline 75 & 75,26 & 2,72 & 1,60 & 1,15 & 0,42 \\
\hline
\end{tabular}

(1993) e NRC (1996) para o macho não-castrado, calcularam-se as exigências diárias de energia metabolizável para mantença. Em seguida, dividindose por 0,82 foram obtidas as exigências de energia digestível (ED). Considerando-se que o valor energético de um quilograma de NDT equivale a 4,409 Mcal de ED, obtiveram-se as exigências de NDT para mantença, dividindo-se as exigências de ED por 4,409 (Tabela 2).

Considerando-se o valor obtido no presente trabalho para $\mathrm{K}_{\mathrm{m}}$ igual a 0,59 , acrescendo $15 \%$, por se tratar de machos não-castrados, como recomendado pelo NRC (1996) e AFRC (1993), e tomando o valor de $77 \mathrm{Kcal} / \mathrm{kg}^{0,75}$ como energia líquida de mantença, as exigências de energia metabolizável para mantença seriam de $150,7 \mathrm{kcal} / \mathrm{kg}^{0,75}$; as exigências de energia digestível, de $183,7 \mathrm{kcal} / \mathrm{kg}^{0,75}$; e as de NDT, de $41,67 \mathrm{~g}$ de NDT $/ \mathrm{kg}^{0,75}$.

$\mathrm{Na}$ Tabela 3, são apresentados os valores das estimativas de energia metabolizável em Mcal por quilograma de ganho de peso corporal vazio (GPCV), de bovinos $\mathrm{F}_{1}$ Simental $\mathrm{x}$ Nelore, obtidos para as diferentes eficiências de utilização da energia metabolizável.

As exigências de energia metabolizável aumentaram, à medida que se elevou o peso corporal, para todos os níveis de concentrado. Da mesma forma, o AFRC (1993) mostrou aumento nas exigências de EM de 79 para $95 \mathrm{MJ} /$ dia para ganho de um quilograma, à medida que o peso se elevou de 300 para $400 \mathrm{~kg}$. Observou-
Tabela 2 - Exigência diária de mantença de energia metabolizável (EM) e energia digestível (ED) e exigências de NDT, para bovinos $F_{1}$ Simental $x$ Nelore

Table 2 - Daily maintenance requirement of metabolizable energy (ME) and digestible energy (DE) and requirements of $T D N$, for $F_{1}$ Simental $x$ Nellore bulls

\begin{tabular}{llccc}
\hline PV & PCV & EM(Mcal/dia) & ED(Mcal/dia) & NDT(kg/dia) \\
$L W$ & $E B W$ & $M E($ Mcal/day) & $D E($ Mcal/day) & $T D N($ kg/day) \\
\hline 350 & 287,5 & 10,48 & 12,78 & 2,89 \\
400 & 338,3 & 11,83 & 14,43 & 3,28 \\
450 & 389,0 & 13,14 & 16,03 & 3,63 \\
500 & 439,7 & 14,41 & 17,57 & 3,99 \\
\hline
\end{tabular}

Tabela 3 - Estimativa da exigência de energia metabolizável (EM), de bovinos $F_{1}$ Simental x Nelore, obtida para as diferentes eficiências de utilização da EM

Table 3 - Metabolizable energy requirement estimate of $F_{1}$ Simental $x$ Nellore bulls, obtained for the different efficiency of ME utilization

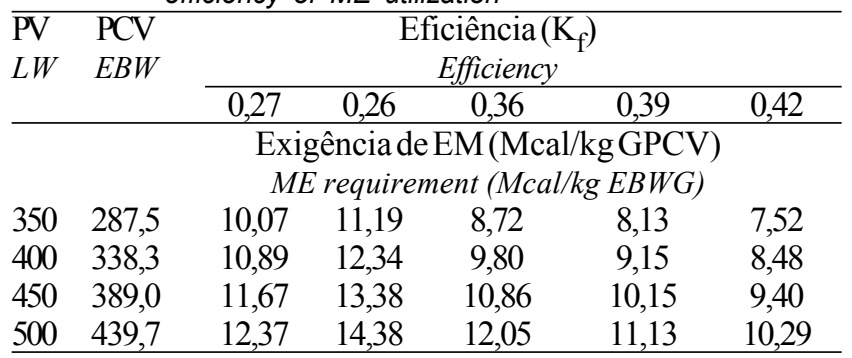

se decréscimo nas exigências com o aumento do nível de concentrado nas rações, para mesmo peso, em virtude do aumento da eficiência de utilização da EM.

As exigências totais de energia metabolizável (mantença + ganho de $1 \mathrm{~kg}$ de PCV), obtidas para animais de 400 e $500 \mathrm{~kg}$ de peso vivo, considerandose o nível de $62,5 \%$ de concentrado $(2,58 \mathrm{Mcal} / \mathrm{kg}$ MS) e eficiência de utilização $\left(\mathrm{K}_{\mathrm{f}}=0,39\right)$, foram de 20,98 e 25,54 Mcal, respectivamente. Estes valores foram próximos aos recomendados pelo AFRC (1993), para animais de maturidade tardia e de pesos correspondentes, para ração com 2,60 Mcal/kg MS, que são de 19,83 e $23,18 \mathrm{Mcal} /$ dia.

A partir dos dados da Tabela 3, as exigências de NDT para ganho de $1 \mathrm{~kg}$ de PCV foram calculadas dividindo-se as exigências de energia metabolizável por $0,82 \mathrm{e}$, posteriormente, dividindo-se as exigências de energia digestível por 4,409. Os resultados são apresentados na Tabela 4. 


\section{Rev. bras. zootec.}

As exigências totais de NDT (mantença + ganho de $1 \mathrm{~kg}$ de PCV), obtidas para animais de $450 \mathrm{~kg}$ de $\mathrm{PV}$, em média, foram de $6,70 \mathrm{~kg}$ de NDT/dia. O NRC (1984) recomendou consumo de $6,32 \mathrm{~kg}$ de NDT/dia para ganho de peso de $0,91 \mathrm{~kg} / \mathrm{dia}$, para bovinos nãocastrados, de porte grande, com peso de, aproximadamente, $450 \mathrm{~kg}$.

Tabela 4 - Estimativa da exigência de nutrientes digestíveis totais (NDT), de bovinos $F_{1}$ Simental $x$ Nelore, obtida para os diferentes níveis de concentrado nas rações

Table 4 - Total digestible nutrient requirement estimate (TDN), of $F_{1}$ Simental x Nellore bulls, obtained for the different levels of concentrate in the diet

\begin{tabular}{lllllll}
\hline PV & PCV & \multicolumn{5}{c}{$\begin{array}{c}\text { Nível de concentrado na ração (\%) } \\
\text { Level of concentrate in the diet }\end{array}$} \\
\cline { 3 - 7 } & EBW & 25 & 37,5 & 50 & 62,5 & 75 \\
\cline { 3 - 7 } & & \multicolumn{5}{c}{ Exigência de NDT(kg/kg GPCV) } \\
& \multicolumn{5}{c}{ TDN requirements $(\mathrm{kg} / \mathrm{kg} E B W G)$} \\
\hline 350 & 287,5 & 2,79 & 3,10 & 2,41 & 2,25 & 2,08 \\
400 & 338,3 & 3,01 & 3,41 & 2,71 & 2,53 & 2,34 \\
450 & 389,0 & 3,23 & 3,70 & 3,00 & 2,81 & 2,60 \\
500 & 439,7 & 3,42 & 3,98 & 3,28 & 3,08 & 2,84 \\
\hline
\end{tabular}

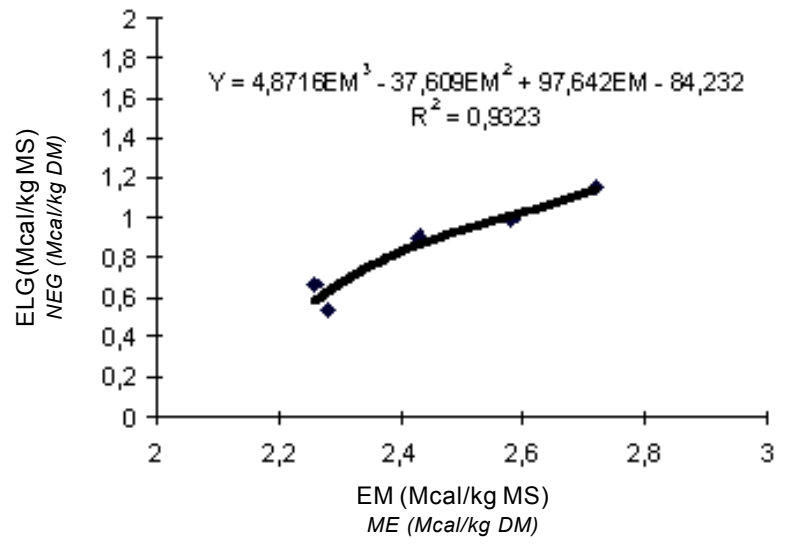

Figura 1 - Estimativa da energia líquida de ganho (ELG), em função do teor de energia metabolizável (EM) das rações.

Figure 1 - Estimate of the net energy of gain (NEG), on the metabolizable energy content in the diets (ME).

\section{Conclusões}

As eficiências de utilização da EM para ganho $\left(\mathrm{K}_{\mathrm{f}}\right)$ foram estimadas em 0,$27 ; 0,26 ; 0,36 ; 0,39$; e 0,42 , respectivamente, para as concentrações de EM de 2,$28 ; 2,26 ; 2,43 ; 2,58$; e 2,72 Mcal/kg MS, obtidas para os níveis de $25 ; 37,5 ; 50 ; 62,5$; e $75 \%$ de concentrado.

As exigências totais de energia metabolizável, obtidas para animais de 400 e $500 \mathrm{~kg}$ de PV, com ganho de $1 \mathrm{~kg}$ de PCV, considerando-se eficiência de utilização $\left(K_{f}=0,39\right)$, foram de 20,98 e 25,54 Mcal, respectivamente.

As exigências de EM, ED e NDT para mantença foram calculadas em 150,7; 183,7; e 41,67g/ $\mathrm{kg}^{0,75}$.

As exigências totais de NDT, obtidas para animais de $450 \mathrm{~kg}$ de PV com ganho de $1 \mathrm{~kg}$ de PCV, foram de $6,70 \mathrm{~kg} /$ dia.

\section{Referências Bibliográficas}

AGRICULTURAL AND FOOD RESEARCH COUNCIL AFRC. 1993. Energy and protein requirements of ruminants. Wallingford: Commonwealth Agricultural Bureaux International, $159 \mathrm{p}$.

BOIN, C. Alguns dados sobre exigências de energia e de proteína de zebuinos. In: PEREIRA, J.C. (Ed). SIMPÓSIO INTERNACIONAL SOBRE EXIGÊNCIAS NUTRICIONAIS DE RUMINANTES, 1995, VIÇOSA, MG. Anais... Viçosa, MG: JARD, p. 457-465, 1995.

COELHO DA SILVA, J.F., LEÃO, M.I. 1979. Fundamentos de nutrição de ruminantes. Piracicaba, Livroceres, 380p.

FERREIRA, M.A., VALADARES FILHO, S.C., COELHO DA SILVA, J.F. et al.1999a. Consumo, conversão, ganho de peso e características da carcaça de bovinos $\mathrm{F}_{1}$ nelore-simental, alimentados com diferentes níveis de concentrado nas rações. Rev. bras. zootec., 28(2):343-351.

FERREIRA, M.A., VALADARES FILHO, S.C., COELHO DA SILVA, J.F., et al.1999b. Composição corporal e exigências líquidas de proteína e energia para ganho de peso de bovinos $\mathrm{F}_{1}$ nelore - simental, não-castrados, alimentados com rações contendo diferentes níveis de concentrado. Rev. bras. zootec., 28(2):352-360.

FONTES, C.A.A. Composição corporal, exigências líquidas de nutrientes para ganho de peso e desempenho produtivo de animais zebuinos e mestiços europeu - zebu. Resultados experimentais. In: PEREIRA, J.C. (Ed). SIMPÓSIO INTERNACIONAL SOBRE EXIGÊNCIAS NUTRICIONAIS DE RUMINANTES, 1995, VIÇOSA, MG. Anais... Viçosa, MG: JARD, p.419-455, 1995.

GARRET, W.N, MEYER, J.H., LOFGREEN, J.P. 1959. The comparative energy requirements of sheep and cattle for maintenance and gain. J. Anim. Sci., 18(2):528-547.

GARRET, W.N. 1980. Factors influencing energetic efficiency of beef production. J. Anim. Sci, 51(6):1434-1440.

HARRIS, L.F. 1970. Nutrition research technique for domestic and wild animal. V.1, Logan, Utah, paginação descontínua.

LANA, R. de P. Composição corporal e exigência de energia e proteina e de macroelementos minerais ( $\mathrm{Ca}, \mathrm{P}, \mathrm{Mg}$, Na e K) de 


\section{FERREIRA et al.}

novilhos de cinco grupos raciais, em confinamento. Viçosa, MG: UFV. 134p. Dissertação (Mestrado em Zootecnia) Universidade Federal de Viçosa, 1991.

LOFGREEN, G.P., GARRET, W.N. 1968. A system for expressing net energy requeriment and feed values for growing and finishing beef cattle. J. Anim. Sci., 27(3):793-806.

NATIONAL RESEARCH COUNCIL - NRC. Nutrients requirements of beef cattle. 6.ed. Washington, D.C., 1984.90p.

NATIONAL RESEARCH COUNCIL - NRC. 1996. Nutrients requirements of beef cattle. 7.ed. Washington, D.C., 242p.

NATIONAL RESEARCH COUNCIL - NRC.1981. Nutritional energetics of domestic animals. 2 ed. Washington, D.C., 54p.

RATTRAY, P.D., JOYCE, J.P. 1976. Utilization of metabolizable energy for fat and protein depositation in sheep. J. Agric., 19(2):299-305.

ROBELIN, J., GEAY, Y. 1983. Body composition of cattle as affected by physiological status, breed, sex and diet. In: GILCHRIST, F.M.C., MACKIE, R.I. (Ed). Herbage nutrition in the subtropics and tropics. The Science Press, Pretoria South Africa, p.525 - 548.
SNIFFEN, C.J., O'CONNOR, J.D., VAN SOEST, P.J. et al. 1992. A net carbohydrate and protein system for evaluating cattle diets: II Carbohydrate and protein availability. $J$. Anim. Sci., 70(11):3562-3577.

SOLIS, J. C., BYERS, F.M., SCHELLING, G.T. et al. 1988. Maintenance requirements and energetic efficiency of cows of different breeds types. J. Anim. Sci., 66(3): 764-773.

Recebido em: 26/06/98

Aceito em: 09/09/98 